\title{
CITIZENSHIP AMENDMENT ACT: DIGITAL ACTIVISM ON TWITTER; A CORPUS-BASED TEXTUAL ANALYSIS OF TWEETS ON CAA
}

\author{
Ms. Geetika Vashishata \\ Assistant Professor, Faculty of Media Studies and Humanities \\ Manav Rachna International Institute of Research Studies, Faridabad \\ Prof. Umesh Arya \\ Professor, Department of Communication Management \& Technology \\ Guru Jambheshwar University of Science \& Technology Hisar
}

\begin{abstract}
This article is an attempt to understand how digital activism was used to express dissent towards the CAA 2019 that proposed citizenship based on religious identity. The study analyses the trending tweets on CAA through the corpus method. The data analysis showed that how Twitter is used both by the citizens and political parties to promote their views. The majority of Twitterati expressed its discomfort towards the Act that was passed hurriedly by stressing heavily on its "unconstitutionality" \& "non-secularity". The pertinent questions of secularism, citizenship, immigration were found to be poorly dissipated and hateful hashtag movements ruled the discourse. The whole discourse was found to be extremely rigid over the issue of nationality and citizenship status of Muslims and NRC. The statistically significant scores of tests like collocate, N-grams, word clusters, and concordances too showed similar results with an inclination towards negative sentiments for the Act.
\end{abstract}

Keywords- Corpus Analysis; Twitter; Digital Activism; Social Media; Citizenship; Immigration; Sentiment Analysis.

\section{INTRODUCTION}

Citizenship is a 'consolidated and enlarged civic, social, political , and intercultural right' given to each citizen (Caves, 2004). It should be granted irrespective of caste, class, gender, race, or religion. However, in India, the question of citizenship is always an 'ambiguous' and 'contested' concept (Nirija, 2019). 'Religious identity', 'ethnicity', 'the impact of partition and migration', always had a bearing on the rights over Indian citizenship (Sharma, 2019).

The Indian Constitution guaranteed citizenship to all of its residents and made no distinction based on religion. As per the Citizenship Act passed in 1955, whosoever is born on Indian land after 1950 is an Indian citizen. However, for individuals, from other countries, a means of naturalization was given after twelve years of residency in the country. Later, this law got amended in 1987. Then Rajiv Gandhi government said mere birth on Indian soil is not sufficient, 'at least one parent' has to be Indian to grant the Indian citizenship status. It got further amended with 'both the parents'."(Gupta, 2019). The Congress government never made any distinction based on caste and religion. Nevertheless, it signed the 'Assam Accord' to force Bangladeshi immigrants to return to their home state irrespective of their religion as a few north-eastern regions had complained of ethnic, cultural and political tampering due to Bangladeshi immigrants, including Hindus. Interestingly, the accord was never actualized neither NRC (The National register of citizens) was implemented. Rather, the Congress government encouraged settlers and immigrants because they were vote-banks. Quite contrary to the Congress, the Bharatiya Janata Party government always talked about protecting Hindus of undivided India who are being religiously persecuted in the neighbouring countries. They promised it in their election manifestos as well.

The BJP government brought the Citizenship Amendment Bill in 2016 with a rider of religion, but it lapsed. The same law was passed in December 2019 in the form of the Citizenship Amendment Bill, 2019. 'We promise to offer Indian citizenship to individuals of religious minority communities from neighbouring countries who suffered religious persecution" (BJP, 2019). 
The law states that people belonging to Hindu, Buddhist, Sikh, Parsi, Jain and Christian, who flew the neighbouring countries of Pakistan, Bangladesh or Afghanistan, in the fear of religious persecution; can apply for India citizenship if they have been living in India as a refugee for at least five years, on or before December 31, 2014. The Act has amended the Citizenship Act 1955 and relaxed the earlier requirements for citizenship by naturalization (living in India) from 12 years to five years.

The law selectively excludes persecuted minorities like Ahmediya Muslims from Pakistan, the Rohingya Muslims of Myanmar, the Uyghur Muslims from China, and many others. The Act exempts the tribal areas of Assam, Meghalaya, Tripura; and areas regulated through the Inner Line Permit, which include Arunachal Pradesh, Mizoram, Manipur and Nagaland.

Since the Act granted citizenship based on religion, challenging the basic rubric of the Indian Constitution i.e. Secularism, it created an uproar in the country. The law was further combined with another- NRC. Ironically, it was reported from Intelligence bureau records, that the act will benefit only 31,313 people from non-Muslim minorities that include 25,447 Hindus, 5,807 Sikhs, 55 Christians, two Buddhists and two Parsis(Gupta 2019).

\section{Digital Activism}

The Internet now is called a 'master medium' because of 'its ability to create a hybrid of the traditional vertical one-way medium and a two-way communication horizontal feedback' (Selnow, 1998). It has the power of converting local themes into global issues. Some of its basic characteristics are global reach, speed, immediacy, dialogue, visibility, engagement, contact, connection, collectivity and shared understanding (Mendes, K., Ringrose, J., \& Keller, J., 2018). Due to this, a new form of digitally-based social initiatives have been gaining momentum in the world, which is reinventing social activism (De Moraes et al. 2020)

The influence of digital activism was first felt at the global level after WikiLeaks in 2010. Arab Spring, Occupy Wall Street!, \#metoomovement, \#FeesMustFall all are the offshoot of this event only. (Bosch T.,2016).
In developing countries like India too, this activism is palpable. Triggered by technological advancements worldwide and locally, digital activism found its first mention in Indian news in 2012 when a Puducherrybased businessman was arrested for a tweet. (Aljazeera, 2014). In India, it had a chequered beginning. First used during the Anna movement, it had to face state suppression; then it became a social tool for mass protest during the Nirbhaya case, where a young paramedic was raped and murdered; then it became a political tool in the hands of Arvind Kejriwal, now Delhi Chief Minister, who used it to catapult to power. Lately, it was used by Narendra Modi, the Indian Prime Minister in his election campaigns to win the Lok Sabha elections in 2014 and 2019. Mr Modi joined Twitter in 2019 and now he is the most followed politician after former US President Barack Obama and current US President Donald Trump.

It is all because of the internet and mobile growth in India. India is the fifth-largest economy and will touch a mark of 900 million people as its electorates in 2020. It is the second-largest market in terms of 430 million smartphone users. (Kantar IMRB Report, 2019) Internet users have registered an annual growth of $18 \%$ in 2018 in India and are expected to cross 630 million by the end of 2020 (ibid, 2019). Internet is penetrating its roots in India and internet users are increasing day by day. The Internet on mobile and low mobile tariffs has spurred this speed. In this scenario, digital activism has an important role to play. It is giving space not only to activists to voice their opinions but also to the political parties to chart out their political campaigns to win the trust of the people and get mass support (Sachdeva et al. 2019).

\section{REVIEW OF LITERATURE}

The advent of the web has suddenly increased the political participation and activism ( Morozov (2009, 2011) and Dean (2005) for an individual, who was hitherto scared of moving to the streets for protests. These digital tools are often used to initiate, manage, or control risk or crisis (Veil, Buehner, \& Palenchar, 2011). They provide "greater access to information, more opportunities to interact publicly and enhanced ability to initiate collective action" (Shirky, 2011). 
Vegh categorizes Digital activism as a phenomenon "largely enabled by the new media (internet and mobile technology), and more specifically the phenomenon of social media". Kaplan and Haenlein (2010) defined it as "a group of internet-based applications that repose on the ideological and technological foundations of Web 2.0 which allow the creation and exchange of user-generated content". Facebook, Twitter, LinkedIn, Pinterest, Google Plus+, YouTube, Tumblr, Instagram, Flickr and WhatsApp are a number of examples.

As per Gerbaudo (2012) “within contemporary social movements, social media have been employed to generate a new experience of public space, staged against the background of a society of dispersion". "The study revealed that the socio-economic and political issues discussed by the online protesters motivated offline protesters during the protests" (ibid, 2012). "The social media would allow the people of the region not only to have access to alternative and independent news information but also to gradually increase the pressure for democratization and liberal reforms" (Eickelman and Anderson, 2003; Lynch, 2006). Blossom (2007) stressed that "web 2.0 is a highly scalable, accessible and cheap technology, which enables individuals not only to communicate with groups of other individuals but also to influence groups of other individuals as they share ideas, activities, events and interests within their networks." According to Vegh (2003), "internet activism is 'a politically motivated movement relying on the internet' using strategies that are either internet-enhanced or internet-based". Rabindranath \& Kapil (2015) further mentioned "three types of internet activism - awareness and advocacy, mediated mobilization and hacktivism." Ekwo (2011) found that "people used keywords on Twitter or Facebook to provide a customized or coded term to support the resistance, create awareness, cultivate networks of activists, and meeting spots". Brennan (2012) said, "Digital communications technologies are transforming activist politics." Bennett \& Segerberg (2012) opined that "a principal feature of digital activism is that it is powered by the possibility of personal expression and the sharing of individual ideas on a large scale."
The researcher could not find much literature on corpus-based quantitative or qualitative research in Indian settings.

\section{THEORETICAL FRAMEWORK}

The study of digital activism on Twitter is based on the framework of three theories: new social movements, media ecology and social presence theory. "The new social movements are a shift from the old politics of social and economic security to the new politics of participation, individual selfrealization and human rights." (Habermas, 1987)

The most integral part of such "contemporary movements are the construction of collective identity" (Melucci, 1989). And Digital media activism is all about creating a politics of the collective identities and collective actions. The network of such activism is comprised of various groups, different sectors and provides a forum for the counter-hegemonic force. (Carroll and Ratner, 1996).

This activism is only possible through the networks of communication, possible by technological inventions. A communication network consists of "interconnected individuals who are linked by patterned communication flows" (Rogers, 1986) and share information in the "interpersonal communication structure' (ibid). The study of such networks or media ecology i.e. communication structure, content, use of technology and their effects on human environments makes an important discourse (McLuhan, 1962). Media ecology looks into how media of communication affect human perception, understanding, feeling, and value. Another theory that has roots in this study is the Social Presence Theory (Short, Williams and Christie, 1976). Social presence is a very powerful tool and realization. "A communicator's sense of awareness of the presence of an interaction partner" and an opportunity to learn about other person's characteristics, qualities and inner states (Short et al., 1976) leads to better perception, interaction and social identity, which is available through new digital platforms only.

\section{THE STUDY}

Citizens are adapting to various social media platforms as tools for participation and express their voices in civic and democratic 
processes (Ahmed, Jaidka, Cho, 2014) and when it comes to an issue of national and global concern, the value of such public contribution increases manifold. The issue of CAA that is going to impact several lives in the country is of the utmost importance from the perspective of research.

Since the Internet is also serving as the "repertoire of collective action" (Tilly 1984), it is important to study how these webtechnologies and social media platforms particularly Twitter are functioning as a means of mobilizing people, ideas and converting them into collective action. It is also a matter of great interest to see what kind of content (voices) these digital activists are putting forth. So, this researcher decides to undertake this study to understand the discourse on the CAA issue on Twitter. The limitations of the corpus linguistics (subjectivity, representational text and reflexivity) are also applicable here.

\section{RESEARCH OBJECTIVES}

1. To study how people (activists) used Twitter to express their dissent and become a part of the digital activism against the passed law.

2. To understand how political leaders have used Twitter to gather support for the controversial law.

3. To understand what kinds of issues have emerged in the discourse.

4. To understand in which context the tweets were used the most.

5. To understand what were the overwhelming sentiments of the tweets discourse.

\section{RESEARCH METHODOLOGY}

A corpus-enabled content analysis method was employed to find the results. "Content analysis may be defined as a methodology by which the researcher seeks to determine the manifest content of the written, spoken or published communications by a systematic, objective and quantitative analysis" (Zito, 1975: 27). A detailed quantitative textual analysis was done on the tweets' corpus in terms of word frequency, keywords and lexical diversity to understand recurring words or concerns of the CAA protests.

A detailed study was also undertaken on the corpus to understand the context by analyzing cluster words, collocates, clusterts/N-gram, frequency and KWIC (Key Word in Context) in concordances.

The lexical density of tweets shown in the study would inform about the richness of the text. The word listing (along with positive, negative and neutral words) would reveal the nature of discourse. The collocates would help us in analyzing the relative tendency of the occurrence of a node word (caa, cab) with other words (Sinclair, 1991). The word clusters and N-grams (the group of software-defined words) would indicate prominent thoughts. The "keyword in context" function would show the proper textual context in which the desired keyword is chosen.

At the same time, the sentiment analysis of the tweets would showcase the tone and polarity of the text and disposition towards the issue and the overall impact. (Jurafsky, n.d.)

The AntConc software was used to conduct the content analysis on the tweets corpus. Applications of textual functions like collocations, keywords, concordances and others are used to probe research objectives.

Reference period- First week of the digital protests starting from 09 December (when the CAB bill was introduced in the Lok Sabha) till 15 December was chosen as the reference period for the study. This was the best period to record the most genuine and initial reactions of the people.

For the second objective of studying i.e. political participation of the political leaders, tweets of political leaders: Prime Minister Narendra Modi, Home Minister Amit Shah, Rahul Gandhi, and Twitter handles of BJP and Congress was studied from December 1, 2019 to April 30, 2020.

Sample selection - The sample comprised 38591 tweets having the "caa" and "cab" as the unit of analysis. The tweets were collected with the help of Mozdeh, tweet analysis software. A total of 38591 tweets were, out of which a considerable number were the retweets.

A total of 119 tweets of major political leaders( @narendramodi, @AmitShah and $@$ RahulGandhi) and their party handles(@BJP4India and @INCIndia) were 
also collected and studied. These were extracted from their Twitter handles directly.

Statistical methods - The study employed the tests like frequency, percentage, type to token ratio for lexical density; collocates, word clusters and N-grams (all corpus statistics) for contextual understanding and Google Add on App named "Text Analysis text2data.com" for sentiment analysis.

\section{FINDINGS AND DISCUSSIONS}

The findings have been presented below as per the research objectives. Two kinds of findings have been discussed here. First reveals the nature of participation by people on the issue of CAA on Twitter. It was presented with the help of tests like frequency, word clusters, Ngrams and sentimental analysis etc. The second showcased how political leaders use Twitter to run a campaign on CCA.

Political Communication- Twitter was used as a potent tool for political communication. McNair (2017) regards political communication as a tool to influence the political environment and calls it the "incorporation of all kinds of communicative practices by all kinds of political organizations".

Both BJP and Congress used Twitter but BJP used it more effectively to put across its point of view behind the Act. Home Minister Amit Shah and Prime Minister Narendra Modi were found to be proactive on Twitter in comparison to Congress Party President Sonia Gandhi and Rahul Gandhi to persuade people about the right intentions of the government behind the Act. Most of the tweets, studied by this researcher, are a kind of clarification and assurance from Mr Modi and Shah about the zero threat to Indian Muslim Citizenship. Amit Shah was the most active leader among all followed by Mr Modi. He tweeted almost
17 tweets during the period. Each tweet had some media link that showed the Home Minister talking to people about the futile uproar about the Act. On the other hand, Rahul Gandhi tweeted only once during the period and there was no tweet from the sides of Sonia Gandhi and Priyanka Gandhi. However, Twitter handles of both the parties were active during the period, countering each other's claims. Few examples of tweets are:

"Nehru-Liaquat pact signed in 1950 protected religious minorities in Pakistan from discrimination.

Why did a secular and visionary leader like Nehru use the term 'religious minorities' and not 'all minorities" @BJP4India.

"I want to tell the 130 crore people of India with full responsibility that CAA will not affect any citizen of India in any way: PM Modi \#PMInLokSabhaities'?"

"CAA will not impact any Indian practicing any faith. \#PMInLokSabha"(BJP4India, Twitter) I assure every person from the minority class that CAA only provides citizenship, and takes nothing away. It won't affect you in any way: Union Home Minister Shri @AmitShah\#AarNoiAnnay."

"Across India, many young men \& women have been wounded \& even killed while protesting against the CAA. I urge our Congress party workers to meet the victim's families \& provide them with all possible assistance. On Saturday I met the families of 2 young martyrs in assam.@RahulGandhi." Table 1 and 1.1 shows details of political tweets.

The focus in the tweets of the BJP was on "convincing people that CAA and NRC will not be affecting the present citizenship status

Table 1: Tweets by political leaders

\begin{tabular}{|c|c|c|c|c|c|}
\hline S.No & User Name & $\begin{array}{c}\text { Number of } \\
\text { Tweets }\end{array}$ & $\begin{array}{c}\text { Overall } \\
\text { Retweets }\end{array}$ & $\begin{array}{c}\text { Overall } \\
\text { Likes }\end{array}$ & $\begin{array}{c}\text { Overall } \\
\text { Replies }\end{array}$ \\
\hline 1 & Narendra Modi & 4 & $41.7 \mathrm{k}$ & $175.3 \mathrm{k}$ & $14.3 \mathrm{k}$ \\
\hline 2 & Rahul Gandhi & 1 & $9.8 \mathrm{k}$ & $41.5 \mathrm{k}$ & $203.9 \mathrm{k}$ \\
\hline 3 & Amit Shah & 17 & $180.8 \mathrm{k}$ & $491.9 \mathrm{k}$ & $331.6 \mathrm{k}$ \\
\hline 4 & BJP4India & 95 & $49.8 \mathrm{k}$ & $182.9 \mathrm{k}$ & $10.1 \mathrm{k}$ \\
\hline 5 & INC India & 2 & $.676 \mathrm{~K}$ & $1.545 \mathrm{k}$ & $.151 \mathrm{k}$ \\
\hline
\end{tabular}


Table 1.1: Graphical representation of tweets by political leaders

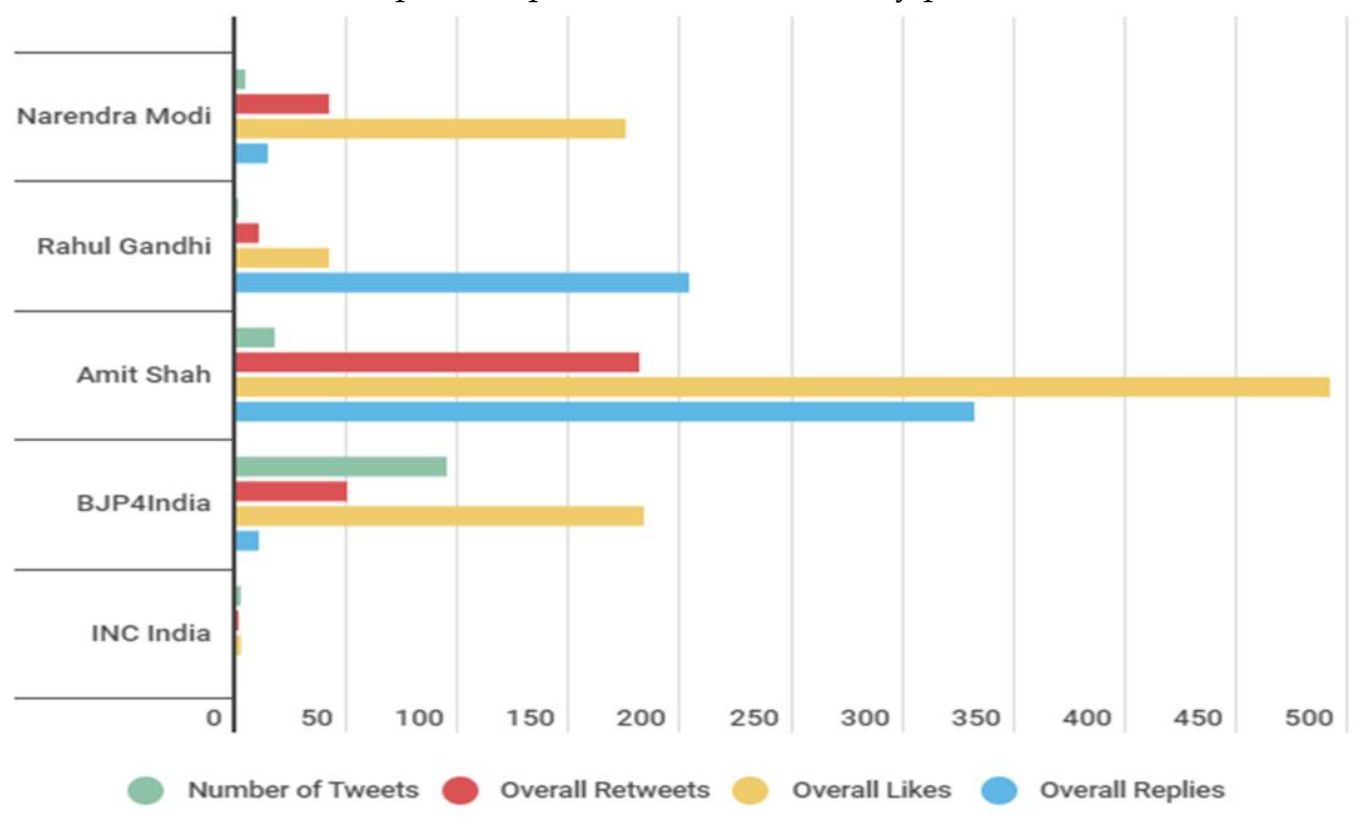

of any religion" and "undoing of injustice meted out to Hindu minorities in three neighboring countries". They wanted to justify their stand on CAA by claiming that they are not doing something new which was not promised earlier by Indian leaders like Nehru during the partition. It is their moral duty and responsibility to undo the injustice meted out to religious minorities who are being persecuted for being Hindu.

People activism on Twitter- The collection of around 38000 tweets in a week itself is evident proof of people's interest in the issue of CAA. People were highly mobilized and divided on their stand on CAA.

Type to Token Ratio- As regards corpus text, "Type to Token Ratio (TTR) is the ratio obtained by dividing the types (the total number of different words) occurring in a text or utterance by its tokens (the total number of words). A high TTR indicates a high degree of lexical variation while a low TTR indicates the opposite." (Thomax, D. (2005). The tweet corpus has $15.54 \%$ TTR which is fairly less thus indicating a poor score. It supports the evidence of less rich corpus text and also proved that the discourse was revolving around a few words only and focused on particular themes only.

Words Frequency - The frequency of words is one of the most fundamental ways to describe the attitude or discourse of a corpus. "Frequency can be an indicator of markedness" (Baker, 2010). The frequency of words demonstrates a possible bias (positive as well as negative) in the text and is denotative of the kind of discourse text has. Hence, its importance cannot be undermined. Table 3 shows the relative frequency of words appearing at least 100 times in the corpus. Words with topmost share were - amendment (25121) citizenshipammendmentbill (15330), Citizenship (19572), assam (11540), (6072) BJP, Muslims (5861), nrc (5750), narendramodi (4657), amitshah (4024), hindu (3580), constitution (2000), religion(1779), immigrants(1230), violence(1228), incindia(1156), religious(1144), assamwantsanswers (1122), unconstitutional(1106).

Though the higher frequency of the first three words is quite obvious owing to the nature of the protests the unusually high occurrence of words like "assam", "bjp", "cabprotest", "Muslim" (used in the context of protests), clearly showed the primacy of words towards the protests which has political and religious hues. High frequency to Assam can be indicative that maximum protests on Twitter came from the Assam region during that particular time period. Domination of words like 'Muslim' and 'BJP' and 'nrc' can be indicative of a debate based on religion and the ruling party's role in it. The names of 
political leaders like Narendra Modi, Amit Shah and even Rahul Gandhi (1576) shows it is a political discourse where political participation was also there.

Table 2: Words with the highest frequency

\begin{tabular}{|r|r|l|}
\hline Rank & Frequency & word \\
\hline 1 & 25121 & amendment \\
\hline 2 & 19572 & citizenship \\
\hline 3 & 15330 & citizenshipammendmentbill \\
\hline 4 & 11540 & assam \\
\hline 5 & 9935 & cabprotest \\
\hline 6 & 6094 & cabbill \\
\hline 7 & 6072 & bjp \\
\hline 8 & 5861 & muslims \\
\hline 9 & 5750 & nrc \\
\hline 10 & 5340 & protest \\
\hline 11 & 4657 & narendramodi \\
\hline 12 & 4024 & amitshah \\
\hline 13 & 3960 & protests \\
\hline 14 & 3580 & hindu \\
\hline 15 & 3179 & pakistan \\
\hline 16 & 2706 & cabpassed \\
\hline 17 & 2507 & government \\
\hline 18 & 2448 & cabprotests \\
\hline 19 & 2339 & congress \\
\hline 20 & 2283 & minorities \\
\hline 21 & 2267 & guwahati \\
\hline 22 & 2260 & protesting \\
\hline & & \\
\hline & & \\
\hline 19 & &
\end{tabular}

Collocates - Collocates is a subclass of set phrases defined in terms of their differentiated specifics concerning set phrases (Igor, 1998). These are the groups of words that tend to occur simultaneously. Basically, a word's meaning is understood by placing it in a relationship with another word, so a study of Collocates helps in understanding the context and tone of the text. Stubbs (2001) mentioned that "repeated patterns show that evaluative meaning is not merely personal and idiosyncratic but widely shared in a discourse community. A word, phrase or construction may trigger a cultural stereotype". However, the corpus researchers must be aware of the fact that all co-occurring words do not carry the same "weight" and the "influence". One of them may outweigh the other in the meaning of construction. Derrida (1981) argues that "a state of power imbalance exists between two positions and one is preferred over the other."

The study of such adjoining words set by the node word (caa) seems to set the agenda and direction of the corpus. The high-intensity collocates of "caa" at two words left and two words right (against a flexible five-word standard practice accepted internationally) showed up interesting associations at a statistical significance level. The corpus has many denotative words appearing more than 10 times.

Words like protests (27), nrc (28), discriminatory (18), assam (18) followed caa.It was also interesting to see the collocates of other keywords that had maximum frequency in the word list. The high-intensity collocates of "cab" are religion basis (254), religion-based (246), India (58), persecuted (48), islam (46), discrimination (43), culture (24) and Nationalism (18). It shows how the whole discourse around cab was based on religionbased discrimination.

The word collocates of the constitution are India (493), redundant (56), religion (50), government (48) democracy (46), protect (36), human (26), violating (20), spirit (16). It reveals how the usages of words pointing towards the erosion of the spirit of the Constitution.

Muslim show collocates like nation (108), democratic (62), direct (46), parties (46), assault (44), liberal (29), Punjab (28), state (26). For secular the high intensity words are india (523), character(72), democratic(62), fabric (48), reject (46), onslaught (44), secular (34), democracy (20), ideology(16), hypocrite(14), pseudo(12).

Word Clusters - These groups of words strictly occur next to the node word (caa) jointly (unlike the collocates which appear within a word range) (Phelan \& Higginson, 1986). Gilquin (2010) argues that two-word clusters are mostly meaningless and misleading and very long clusters (6-8 words) are either too complex or non-interesting. Hence taking a middle path of four words seemed sensible to the researcher. Interestingly, the word clusters results filtered by the AntConc software again validates the findings of the collocational analysis and word frequency analysis. The repeated occurrence of "protests" was found in all the word clusters.

It coexisted with words like "assam", "muslim", "bjp" "amendment" and "religion". Other clusters too had an association with words like assam (name of the city), 'nrc', 'protests', 'ethnicity' and 'culture' etc. All these clusters have a frequency of more than five. This points towards the systematic association of words 
like religion, secular, religion in the twitter discourse on the citizenship amendment bill.

$\mathrm{N}$-grams - "N-gram is defined as a collocation of words that is ' $n$ ' items long. A bigram is a collocation of 2 words, a 4-gram is a collocation of four and so on" (Freund \& Willet 1982). N-grams are purely filtered by the corpus analysis software unlike word clusters and collocates where the researcher has to enter the node word. Hence there is less scope of bias (Gilquin, 2010). 437754 out of 3156961 total words strings (N-grams) (13.8 per cent of the whole text) showed strings like "protests against caa", "fight against nrc", 'muslim religious identity" and "assam culture and ethnic identity" that indicate that the larger portion of the discourse was towards expressing their resentment over the Act.

Frequency of Positive Words versus Negative Words -The corpus had 56683 positive words out of total 3156961 words (1.90 percent) whereas it had 75540 (2.27 percent) negative words. The negative words like 'against', 'protest', 'cabprotest', 'violence', 'unconstitutional', 'persecution' and 'communal' were consistently dominating the text of the corpus whereas there was no such consistent pattern in the positive words. The researcher must clarify here that words per se may not fully indicative of being positive or negative unless the related context is clear. But prima facie, presence of the negative words conveys the impression of negativity here in the corpus. On the positive side, the "peaceful", "support" and "support to persecute" were the words found mention in the corpus text.

Table 3: Frequency of positive words versus negative words

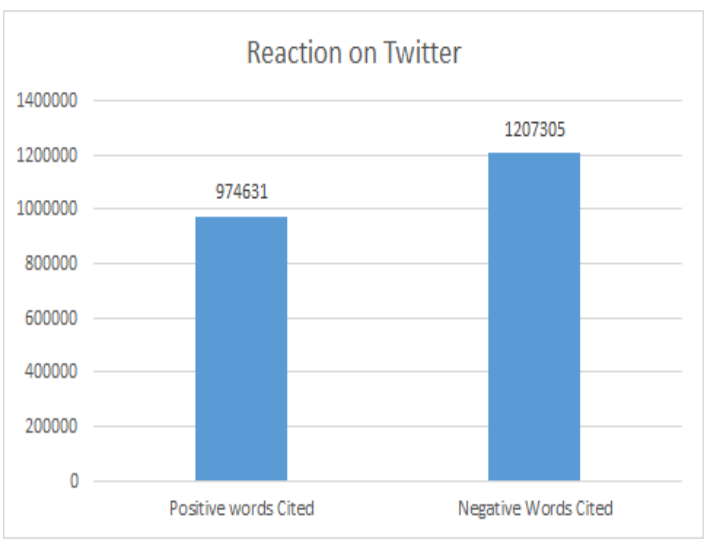

Table 4: Tweets sample with positive words

We Indians stand shoulder to shoulder with @narendramodi ji @AmitShah ji and @BJP4India for \#CAB2019 CONGRATULATIONS to the immigrants who came To India to leave a fearless and peaceful life. Jai Ho.

IIT-B students support Citizenship Amendment Bill even as handful of students from leftist orgs try to protest in campus

@ AmitShah: As the Citizenship Amendment Bill 2019 passes in the Parliament, the dreams of crores of deprived \&amp; victimised people has come true.

@chetan_bhagat Sir don't tell these people..they only know one thing..that is nothing.. People should read the \#CAB sensibly but they don't..and then they protest without any logic.. The govt must make some strong decisions for the country and they are.

@narendramodi CAA manifests India's ethos of harmony and compassion. Sadly, the vested interest groups opposing the Act are now protesting against India's Parliament.

Dear \#AMU \#Jamia students\&and; faculty .salute to your spirit fight against \#CAB @Narendra Modi I want to assure my brothers and sisters of Assam that they have nothing to worry after the passing of \#CAB. I want to assure them- no one can take away your rights, unique identity and beautiful culture. It will continue to flourish and grow.

@narendramodi Lies and more lies- this is what the Congress and its allies are spreading on CAB. The CAB affects no citizen of India. In line with our ethos of assimilation and compassion, it ensures a better life for persecuted minorities from other nations.

The positive words were part of tweets that supported the cause of CAA and the government's claims of giving justice to the persecuted people of non-Muslim religious background on the grounds of partition atrocities. Tweets of some known celebrities like Chetan Bhagat and Prime Minister Narendra Modi and Home Minister Amit Shah showed solidarity and positive words.

However, on the negative word list side words such as "protests", "unconstitutional"," "caa is discriminatory", "religion a criterion a political signal of a terrible narrowing", "religion amounts to a rejection of the Constitution", "muslim, I'm feeling alienated", "NRC against the Secular character", "NRC 
All this because at the centre fascism is ruling".

Table 4: Tweets sample with negative words.

Citizenship Amendment Act Protests Updates: UNHRC says CAA is 'fundamentally discriminatory', global body to analyse possible consequences of law - Firstpost

Those who created a state based on religion, ignoring the forewarnings of people like Savarkar, left Hindu refugees...RT @OpIndia_com: Those who created a state based on religion, ignoring the forewarnings of people like Savarkar.

"Across India, many young men \& women have been wounded \& even killed while protesting against the CAA. I urge our Congress party workers to meet the victim's families \& provide them all possible assistance. On Saturday I met the families of 2 young martyrs in Assam." @RahulGandhi.

Assam News Citizenship (Amendment) Bill: Thousands Defy Curfew In Guwahati As Assam Rages Over Citizenship Bill

@nsui @INCAssam@ndtvindia It's like saying: we will put you in prison but we will not take away your rights. You will continue enjoying the luxury of rights but can't come out of jail. We will decide whether your demands can be met. RT @Krishn_: Asking the judiciary to defend the Constitution \&amp; protect India's soul,

@hangs your head in shame, those parliamentarians who support this atrocious laws.

\#CABProtest \#NoMoreBJP \#NoCAB @himantabi swa @narendramodi @AmitShah WAKE UP ALREADY! Being delusional to such an extent is plain stupid.

Communal Citizenship Amendment Bill! Wanting to study and save

Says 'unconstitutional' \#CAB won't be implemented in Kerala.

However, it can be said that the words per se, do not have positive or negative connotations and it is the context in which they are used that explains all.

Hashtags -Hashtags signify broad themes, and important information in social media communication (Saxton, Guo, Waters, Niyirora, 2015). Hashtag usage is a powerful tool as anybody can use it freely without restriction thus entailing equal participation (ibid). They help in aggregating the floating information (tweets) on a particular topic and translating it into a constructive dialogue.
Many powerful and popular hashtags campaigns were started to garner or counter support in CAA issue. Among all eight top repeatedly used hashtags, a hashtag referenced to citizenship amendment bill cab which had oblique reference to the unjustified passage of the bill. The wrath was against the ruling party BJP who hurriedly brought the bill.

The BJP even tried to bring a hashtag campaign in the name of the \#indiasupportscaa, ironically an-anti campaign \#indiadoesnotsupportscaa was also launched at the same time and got all the vigour. Modi government's \#indiasupportscaa campaign garnered 4.14 lakhs tweets and its contrary campaign \#indiadoesnotsupportcaa 4.44 lakhs tweets. Hashtags were used as a tool to run campaigns in favour and against the CAA. During CAA agitation nine top most hashtags are described in Table 5.

Table 5: Top trending hashtags

\begin{tabular}{|cl|}
\hline \multicolumn{2}{|c|}{ Trending Hashtags(30.3.20) } \\
\hline 1. & \#cabprotest \\
2. & \#citizenshipamendmentbill \\
3. & \#cabpassed \\
4. & \#indiarejectscab \\
5. & \#assamwantsanswers \\
6. & \#indiasupportscaa \\
7. & \#indiadoesnotsupportscaaa \\
8. & \#indiarejectstsnrc \\
9. & \#indiaagainstcab \\
\hline
\end{tabular}

Concordance Analysis - Concordances help in "studying words' meanings in an authentic context and discovering those patterns and meanings, which may not otherwise be visible" (Biber, Conrad, \& Reppen, 1998; quoted in Arkin, 2003). Nation (2001) argues that "the use of concordances provides opportunities for discovery learning, where learners are engaged in words and their usages in real contexts and are challenged to draw generalizations and patterns of the words and their usage".

KWIC (Key Word in Context) is an important measure of qualitative data corpus A random sample of 100 instances of concordances with the node word as "caa" revealed varied people's opinions in the text. Table 6 shows the KWIC. 
Table 6: Frequency of keywords

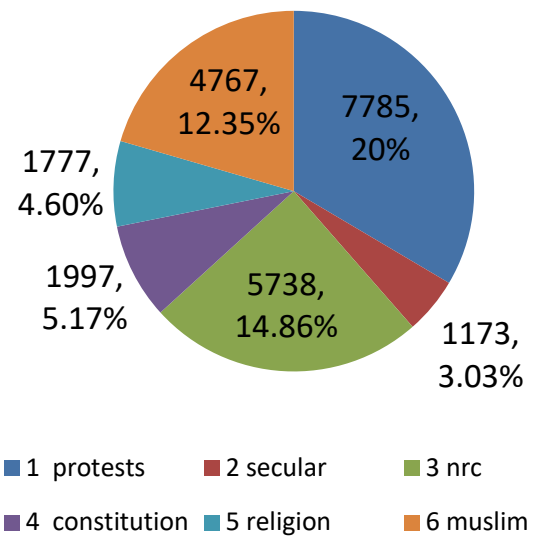

Out of 100 statements, twenty-five had the mention of "protests" as a keyword e.g. "CABProtests spill over to \#Meghalaya | Indefinite curfew imposed in Meghalaya", "CABProtests \#CAB2019 Cheap gimmick to divert from the economic slump.", "Northeast troubles are sponsored by @INCIndia. \#CAB2019 \#", "CABProtests since morning. Is media hiding the news related to \#"," CABProtests \#RahulGandhi \#Amit_Shah_is_New_Jinnah \#CABProtest"," Says 'unconstitutional' \#CAB won't be implemented in Kerala, "\#caaprotestsCitizenshipAmendmentBill has been slammed by rights groups, opposition" etc?

Twelve statements, spurred by nationalistic sentiment were in support of the caa and had keywords like 'democracy' and 'commitment'. “@tavleen_singh It's a fashion nowadays for seditious elements to regularise themselves under the facade of Dissidence \&amp; FoE. Long live Democracy", "Govt is fully committed and accomplishes each $\mathrm{n}$ every election manifestos with full dedication. It was never before. Kudos to @narendramodi \&amp; @ AmitShah for the bill", "Sorry \#RohitSharma I can't see your batting Because last night my favourite batsman is \#AmitShah \#PolitcsLive \#cricketlive \#CAB2019“.

Some are the statements given by the political leaders to clear and propel doubts regarding citizenship. 'Citizenship' was the other most important word that found the reference in 14 tweets.@amitshah “CAA is to give citizenship to religiously persecuted refugees, it is not to take away the citizenship of any Indian. Some parties are spreading rumours and inciting violence for their interest"@RahulGandhi @narendramodi should resign as he is supporting \#CAB @AmitShah, Bro as we have the majority I will be the PM then @RahulGandhi Modiji is much better.

Important references like 'NRC' and 'citizenship', 'religion' were also etched there in the text of the sample tweets," a chance to become Indian citizens. (By @PrabhashRinkoo)", "NRC actually weaponises the State and law enforcement agencies again", "The government's obstinacy in going ahead with citizenship bill is a sad day for Indian democracy because of the legislation that challenges its founding principles of equality and secularism is allowed to be passed. All faith in the Supreme Court now.\#CABProtest".

Out of total 38591 sampled retweets, 7785 (20\%) tweets belong to protests, 5738 (14.86 \%) to nrc, $1997(5.17 \%)$ to constitution, 1777 $(4.60 \%)$ to religion, $4767(12.35 \%)$ to muslim, $1173(3.03 \%)$ to secular.

Table 7 gives a brief snapshot of the concordances i.e. KWIC.

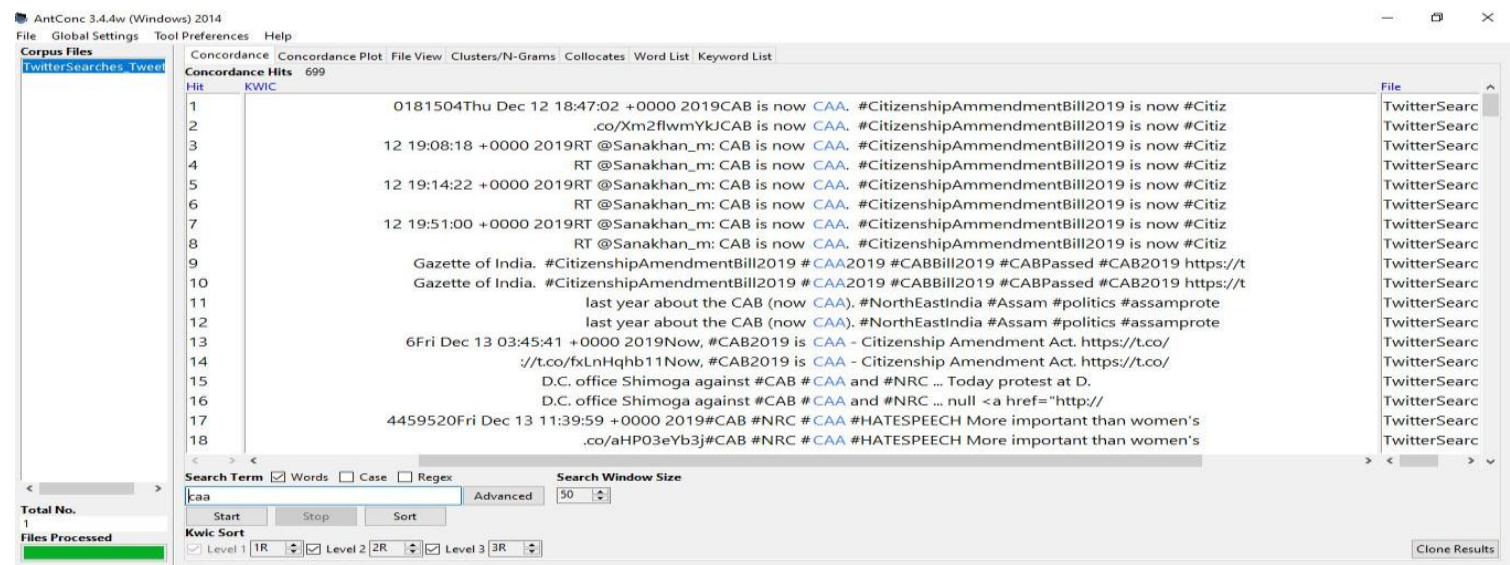




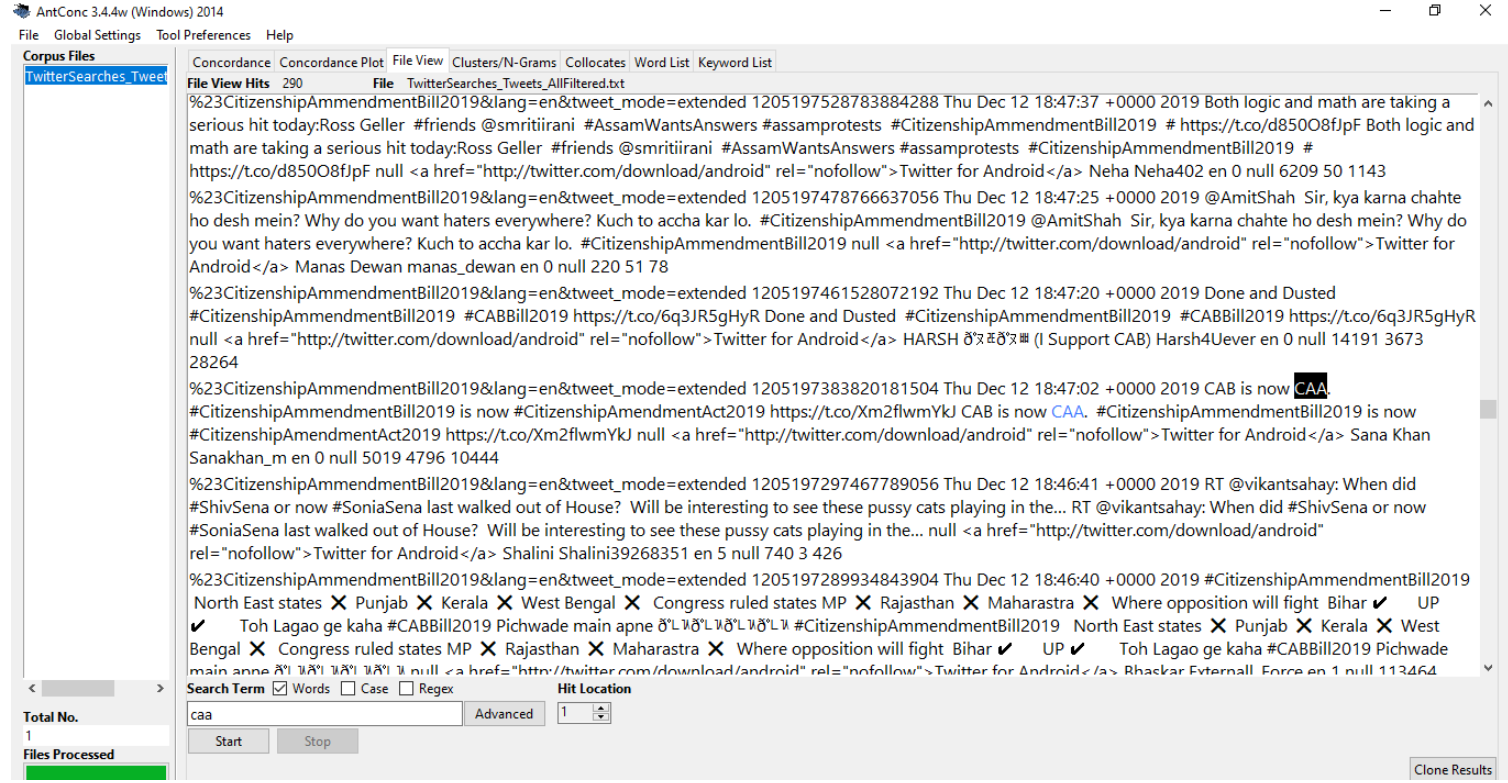

Sentiment Analysis - The sentiment of the tweets represent the attitude, tone \& tenor, slant (positive, negative and neutral) and in a nutshell, overall qualitative judgement attributed to it by the netizens (Jurafsky, n.d.). This technique has a few technical limitations "relating to opinion groupings" which means "lower accuracy and high response errors in classifying textual data" (Rambocas \& Pacheco, 2018). However with sentiment analysis, "researchers can also automatically extract high-quality data on emotional expressions that are measurable, objective and consistent" and it "extracts emotions from the online text but classifies specific problem areas into predefined mutually exclusive categories" (Liu, 2012 \& Rambocas \& Pacheco, 2018 ). The researcher used the "Text Analytics data-totext" app in the google spreadsheet. The same was hand-coded by the coders to arrive at a more objective assessment.

Out of total 38591 tweets, Majority (54\%) were found neutral and the frequency of a neutral word is 4.18 , which means, after every $4-5$ words there is a neutral word. The frequency of positive sentiment is 1.79 and negative sentiment is 2.39 . The overall sentiment of the corpus is found to be tilted a little more towards negative sentiment. It is shown in table 9.

\section{CONCLUSIONS}

The study analysed 38591 tweets including retweets for quantitative attributes. The tweets had a poor lexical diversity means less richness of the text. It reflects more repeated words indicative of a concise, focused and repetitive message. Such findings generally tend to be true in the case of tweets analysis on particular issues as they revolve around a few

Table 9: Sentiment analysis of tweets on CAA

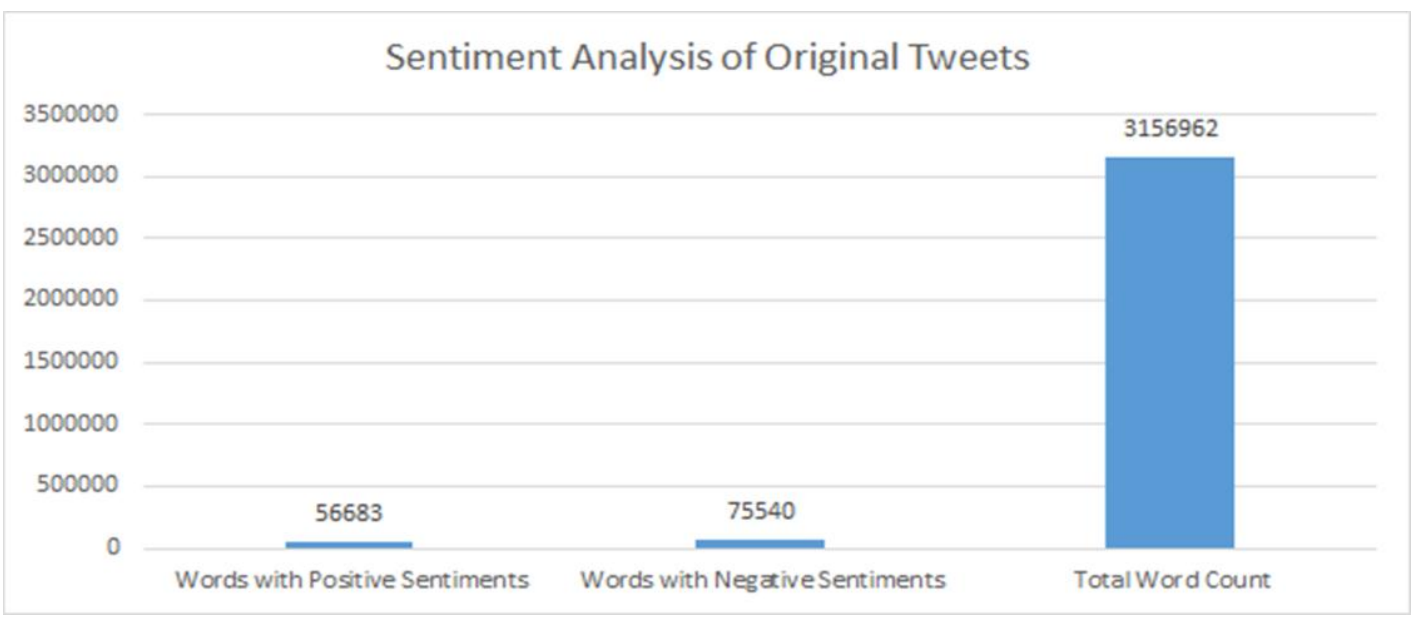


themes. The analysis, in general, was found dissipated with the words like protests, agitation, religion, nrc, communal, secular, constitution, Muslim etc. and in particular, in the word frequency of the corpus.

The findings showed quite a lot of tweets are from political leaders(Modi, Amit Shah and Rahul Gandhi), political organizations like the ruling party (BJP) and the opposition party (Congress) along with normal Twitter activists. This manifests the power of digital platforms like twitter to run, manage and counter political campaigns to form and counter public opinion. The ruling party was squarely blamed for bringing the citizenship bill based on religious identity which was unheard of in the near past of the country.

Inciting protests and not tolerating a new citizenship law introduced based on religion was projected in very harsh 140 characters of tweets. Whereas, the ruling BJP tried to assuage the feeling of Muslim citizens by giving clarification and running a campaign stating that this will not hurt the interests of the Indian Muslims; Congress, some Muslim educational and political organisations tried to escalate into nationwide protests. Unfortunately, with the advent of COVID-19 the whole campaign took the back seat.

The corpus data was consistently reflecting the "protests" attachment to the citizenship amendment bill which had some staunch supporters too. The corpus functions like collocates, word clusters, N-grams etc. repeatedly indicated words like "protests, caa and nrc" with statistical tests of significance on the corpus data. The corpus vocabulary for positive and negative words too confirmed the view of a tilt towards the negative side.

The top eleven words were regarding the "protests" and its derivatives with comparatively less stress on the positive words. The hashtag revolution unleashed on social media too showed the proposition of "discourse concentration" in favour of negative words and its associates. The Twitterati did not mince words on the hurried implementation of the bill which was simply seen as a part of the Hindutva politics agenda. Verdict on Ayodhya- Babri masjid dispute and triple talaq were seen as the precursors of this development. The ruling government tried to blame the Congress and other opposition parties for the mayhem. This was further proved by the sentiment analysis of the tweets in which a large section of the tweets fell into the negative category. Nevertheless, the CAA witnessed a mixed fate in twitter discourse. The agitation could not achieve its purpose as the government had already passed the bill and the sudden outbreak of the COVID 19 took the wind out of the campaign.

The findings also establish a coherent tone with reviewed literature mentioning citizens use social media to voice their dissent against the government, e.g. Arab Spring (Howard \& Hussain, 2013), Egyptian protests (Eltantawy \& Wiest, 2011). \& Tunisian uprising (Breuer, Landman, \& Farquhar, 2015), However, the findings are not in agreement with Eickelman \& Anderson (2003; Lynch, 2006) which mentions "the quality of social media for providing independent and alternative news and gradual pressure building for liberal reforms and democratization on a big scale as these protests could not put "pressure for democratization and liberal reform."

The present study has a limitation that it could not map the whole ecosystem of agitation coverage except twitter and hence the researcher recommends further study on the other media platforms to gauge the trend.

\section{REFERENCES}

Ahmed, S., Jaidka, K., Cho, J., The 2014 Indian Elections on Twitter: A comparison of campaign strategies of political parties, Telematics and Informatics (2016), doi:http://dx.doi.org/10.1016/j.tele. 2016.03.002)

Aikat, D. (2014). The Rise of a Networked Public Sphere: The Role of Social Media in India's Media Landscape. International Journal of Interactive Communication Systems and Technologies (IJICST), 4(1), 61-73.

Baker, P. (2010). Sociolinguistics and Corpus Linguistics: Edinburgh University Press.

Bennett (2012), 'The Personalization of Politics: Political Identity, Social Media, and Changing Patterns of Participation', The Annals of the American Academy of Political and Social Science, 644: 20-39. 
Bennett, W \& Segerberg, A. (2012), 'The Logic of Connective Action', Information, Communication and Society, 15: 739-68.

BJP Election Manifesto 2019 (n.d.). Retrieved from https://www.bjp.org/en/manifesto Retrieved from http://cdn.narendramodi. in/wp-content/uploads/2014/04/

Manifesto2014highlights.pdf

Bruns, A., \& Burgess, J. E. (2011, August). The use of Twitter hashtags in the formation of ad hoc publics. Paper presented at the 6th European Consortium for Political Research General Conference, University of Iceland, Reykjavik.

Breuer, A., Landman, T., \& Farquhar, D. (2015). Social media and protest mobilization: Evidence from the Tunisian revolution. Democratization, 22(4), 764792.

Caves, R. W. (2004). Encyclopedia of the City. Routledge. p. 97Retrieved from https://shora.tabriz.ir/Uploads/83/cms/ user/File/657/E_Book/Urban\%20Studies /Encyclopedia\%20of\%20the\%20City.pdf

De Moraes, G. H. S. M., Pelegrini, G. C., \& Pinheiro, G. T. SOCIAL MEDIA AND PROTESTS ENGAGEMENT: WHAT'S GENDER GOT TO DO WITH IT?

Digital Activism Decoded: The New Mechanics of Change - Mary C. Joyce Google Books. (n.d.). Retrieved from https:/ / books.google.co.in/books?hl=en\& $\mathrm{lr}=\& \mathrm{id}=\mathrm{w} 3 \mathrm{AOzoq7VfIC \& oi=fnd \& pg=PR7}$ \&dq=digital+activism+decoded\&ots $=W$ ne K1HWwfs\&sig=DLskjS4BDqV83_F110siK9 EM

Ekwo, U. (2011, April). Media-political complex in the era of media convergence: Lessons from the Arab Spring. In Media and the Arab Spring Conference, The Clinton Institute of American Studies, University College.

Gilquin, G. (2010). Corpus, Cognition and Causative Constructions: John Benjamins Publishing Company.

Heacock R. (2009, December 1). Twitter Revolution?Retrieved froM http:// rebekahheacock.org/wp content/ uploads/2009/12/Heacock_TwitterRevol ution.pdfcontent/uploads/2009/12/Heac ock_TwitterRevolution.pdf
Higginson, B., \& Phelan, P. (1986). Word Cluster: A Strategy for Synonym Development. Reading Horizons, 26(3), 174-178. Retrieved from http:// scholarworks.wmich.edu/cgi/viewconten t.cgi ?article $=1827 \&$ context=reading_horiz ons

\#IndiaDoesNotSupportCAA takes Twitter by storm. (2020, December 31). Retrieved from https://www.hindustantimes.com/ india-news/indiadoesnotsupportcaa-takes -twitter-by-storm/storySwRmAoj4tEh2DY9OUK0mBJ.html

IMRB, Kantar I-Cube report 2019 retrieved from( 2020, March 31) https://imrbint. com/images/common/ICUBE $\%$ E2\% $84 \%$ A2_2019_Highlights.pdf

Jayal, N.G. (2019), Reconfiguring Citizenship in Contemporary India, Journal of South Asian Studies, 42(1), pp. 34-36 (context: 33-50), doi:10.1080/00856401.2019.1555874

Let's understand the entire issue first \& then react; Journalist Shekhar Gupta explains CAA/NRC as it is for you to opine unbiasedly. (2019, December 19). Retrieved from https://www.edtimes.in/ lets-understand-the-entire-issue-firstjournalist-shekhar- gupta-explains-caanrc-as-it-is-for-you-to-opine-unbiasedly/

Liu, B. (2012), "Sentiment analysis and opinion mining", Synthesis Lectures on Human Language Technologies, Vol. 5 No. 1, pp. 1-167. [Crossref], [Google Scholar] [Infotrieve]

Mairaru, S., Tyagi, S., Azeez, C., \& Sharma, D. C. (2019). Understanding the Print, Web, Television Media Habits and Preferences of Indians: A Uses and Gratification Perspective. Journal of Content, Community and Communication, 9(1), 75-80.

Mendes, K., Ringrose, J., \& Keller, J. (2018). \#MeToo and the promise and pitfalls of challenging rape culture through digital feminist activism. European Journal of Women's Studies, 25(2), 236-246. doi:10.1177/1350506818765318

McNair, B. (2017). An introduction to political communication. Taylor \& Francis.

Prasanto K Roy. (2014, January 6). India's era of digital activism. Retrieved from https://www.aljazeera.com/indepth/opi 
nion/2014/01/india-era-digital-activism20141673434424641.html

Rabindranath, M., \& Kapil, S. (2015). Social media and the Arab Spring. Media Watch, 6(1), 124-132.

Rambocas, M., \& Pacheco, B. G. (2018). Online sentiment analysis in marketing research: a review. Journal of Research in Interactive Marketing, 12(2), 146-163.

Rogers, E. M. (1986). Communication Technology: The New Media in Society. New York: Free

Press.Saxton, G., Guo, C., Waters, R., \& Niyirora, J. (2015). Advocating For Change: The Strategic Use of Hashtags in Social Media Advocacy. Retrieved from http:/ / repository.usfca.edu/cgi/viewcont ent.cgi? article $=1029 \&$ context $=$ pna

Sachdeva, P., \& Tripathi, D. (2019). A Critical Education for 21st Century: A study on Youth and Media literacy. Journal of Content, Community and Communication, 10(9).

Sharma, C. (2019): Citizenship Amendment Bill 2016: continuities and contestations with special reference to politics in Assam, India, Asian Ethnicity, DOI: 10.1080/14631369.2019.1601993

Shirky, C. (2011). The political power of social media: Technology, the public sphere, and political change. Foreign affairs, 28-41.

Sinclair, J. (1991). Corpus, Concordance and Collocation. Oxford: Oxford University Press

Short, J.A., Williams, E., \& Christie, B. (1976). The social psychology of telecommunications. New York: John Wiley \& Sons.

Vegh, S. (2003) Classifying forms of online activism: the case of cyberprotests against the World Bank. In: McCaughey $\mathrm{M}$ and Ayers MD (eds) Cyberactivism: Online Activism in Theory and Practice. London: Routledge: 71-96.

Zito, G. V. (1975). Methodology and meanings: Varieties of sociological inquiry. New York: Praeger.

Zuckerman, E. (2014), 'New Media, New Civics?', Policy \& Internet, 6: 151-68. 